\title{
Presentism, eternalism and where things are located
}

Emanuel Viebahn

Department of Philosophy, Humboldt University of Berlin

\begin{abstract}
In several recent papers, Daniel Deasy has argued that the presentism-eternalism debate is unclear and should be abandoned. According to Deasy, there is no way of spelling out the predicate 'is present' that leads to a satisfactory definition of presentism: on some interpretations, presentism turns out to be compatible with eternalism, on others, it is clearly false or unacceptable for other reasons. The aim of this paper is to show that this line of argument should be resisted: if the predicate 'is present' is spelled out in terms of where things are located, the result is a definition of presentism that is neither compatible with eternalism nor clearly false. There is thus no need to abandon the debate between presentists and eternalists.
\end{abstract}

This is a preprint of an article whose final and definitive form will be published in Synthese. 


\section{Introduction}

A longstanding debate in the philosophy of time concerns the question whether non-present things exist. The main positions in this debate are presentism and eternalism. Presentists hold that only present things exist. Eternalists hold that, in addition, dinosaurs and other non-present things exist. In several recent papers, Daniel Deasy (2017a, 2017b, ms) has argued that this debate is misguided and should be abandoned. Rather than investigating whether non-present things exist, philosophers of time should turn to the following question: Do things come into existence and go out of existence? Two answers to this question are permanentism, according to which everything always exists (and thus nothing ever comes into existence or goes out of existence), and transientism, according to which sometimes something begins to exist and sometimes something ceases to exist.

The main complaint Deasy lodges against the presentism-eternalism debate is that it is unclear because there is no good way of defining presentism. ${ }^{1}$ The traditional definition of presentism runs as follows:

(P) Always, everything is present

Deasy argues that no interpretation of the predicate 'is present' in (P) leads to a satisfactory definition of presentism. On some interpretations, presentism turns out to be trivial and compatible with eternalism, on others, it is clearly false or unacceptable for other reasons. There are no analogous problems in defining permanentism and transientism, the argument continues, so philosophers of time should focus their efforts on the clearer permanentism-transientism debate instead.

If successful, this argument would be a serious problem for a major debate in analytic metaphysics. It is thus unsurprising that it has been criticised by both eternalists, such as Cameron (2016), and presentists, such as Tallant (2017). The aim of this paper is to point to a response to Deasy's argument that has so far gone unnoticed: in dismissing a plausible interpretation of 'is present' and claiming that it is compatible with eternalism, Deasy relies on a mistaken assumption about how eternalists should treat tense. Once this assumption is removed, the interpretation in question permits a clear and helpful definition of presentism and eternalism. There is thus no need to abandon the debate between presentists and eternalists, and the debate

\footnotetext{
1 Timothy Williamson (2013: 24-25) puts forward a similar argument, claiming that the debate between presentists and eternalists is "hopelessly muddled" (25). In what follows, I will focus on Deasy's version of the argument, as it is spelled out in much more detail than Williamson's.
} 
about whether things come into existence and go out of existence should be seen as complementing, not replacing, the debate about whether there are non-present things.

\section{Presentism, eternalism and the restrictor principle}

Deasy proceeds by considering various interpretations of $(\mathrm{P})$ and then arguing that the outcome does not lead to an acceptable definition of presentism. In this section, I will consider one of the interpretations discussed by Deasy (2017a: 385-388, 2017b: 11-13) and the extended argument Deasy puts forward against it, before responding to the argument in the next section.

The interpretation in question runs as follows:

(P1) The sentence 'Everything exists now' expresses a true proposition in every context of utterance.

The underlying idea of this interpretation is that to be present is to exist now; this leads to the sentence in quotes in (P1). The material outside the quotes captures the plausible view that theories in the philosophy of time are always true if true (cf. Deasy 2017a: 380).

Deasy tries to show that (P1) is not a satisfactory definition of presentism because it is trivial, even from an eternalist perspective. To arrive at this conclusion, Deasy (2017a: 386-387; 2017b: 11-13) argues that eternalists must accept the following redundancy principle concerning temporal operators:

\section{Redundancy principle}

(Red) The standard temporal operators are redundant.

If eternalists indeed treat the temporal operator 'now' as redundant, they will take 'Everything exists now' in definition (P1) to be equivalent to 'Everything exists'. Then, however, (P1) is trivially true and consistent with eternalism. So, the argument concludes, (P1) is unsuitable as a definition of presentism.

Deasy's argument relies on the claim that eternalists have to accept (Red). To support this point, he provides an argument that has as its starting point the following principle concerning temporal operators, which eternalists such as Ted Sider (2006: 75-78) seem to accept: 


\section{Restrictor principle}

(RP) The standard temporal operators are implicit quantifiers over instants of time which restrict the explicit individual quantifiers $(\forall, \exists)$ in their scope to things that are located at the relevant instant.

One reason for eternalists to accept (RP) is that it allows them to account for common-sense intuitions about sentences such as (1):

(1) Right now, there exist dinosaurs.

Most people would take (1) to be false. Eternalism is in line with this intuition if the temporal operator 'right now' is interpreted in accordance with (RP) and taken to introduce a restriction to the instant of the utterance. In that case, (1) has the same truth-conditions as (1.1):

(1.1) There exist dinosaurs, located at the present instant.

Thus (RP) allows eternalists to agree with the common-sense view that (1) is false.

Deasy (2017a: 387, 2017b: 12), however, holds that eternalists must reject (RP) because it leads to contradiction. His argument for this claim takes the form of a reductio ad absurdum and is based on the following premises:

Sometimes principle

(SP) If something is the case, then it is sometimes the case.

Non-instantmates

(NIM) There is some $x$ and some $y$ such that there is no instant at which both $x$ and $y$ are located.

(SP) is the temporal version of the modal principle that if something is the case, then it is possible that it is the case. And (NIM) says something about how things are distributed in time; it is true if, for example, Napoleon and Obama are taken to exist and to be non-contemporaneous. (SP) and (NIM) together imply (2):

(2) Sometimes, there is some $x$ and some $y$ such that there is no instant at which both $x$ and $y$ are located. 
And if the temporal operator 'sometimes' in (2) is interpreted according to (RP), (2) is equivalent to the contradictory (3):

(3) For some instant $t$, there is some $x$ and some $y$ located at $t$ such that there is no instant at which both $x$ and $y$ are located.

Deasy then claims that eternalists should not resolve the contradiction by abandoning (SP) or (NIM). He takes (SP) to be immensely plausible ("how could something be the case but never be the case?" (2017a: 387, emphasis unchanged)). And he holds that it would be "absurd" (ibid.) for eternalists to deny (NIM). Eternalists are thus left with the rejection of (RP) as the only way out. If (RP) is rejected, Deasy concludes, eternalists must treat the temporal operators as redundant, and thus accept (Red). And once (Red) is accepted, the definition of presentism (P1) is trivial and consistent with eternalism, as we have seen.

\section{Which restrictor principle for eternalism?}

Deasy's argument against (P1) assumes (i) that eternalists accept (RP), and (ii) that the only alternative to (RP) is (Red). I will now argue that both of these assumptions are mistaken. I will show that there is a different principle concerning the temporal operators that is compatible with what some eternalists say on the matter and that has been explicitly endorsed by other eternalists. This principle does not lead to contradiction given (SP) and (NIM). Furthermore, it is preferable to both (RP) and (Red) because it is in line with how contemporary semanticists treat tense. ${ }^{2}$

Here is the restrictor principle eternalists should, in my view, accept:

\section{Interval restrictor principle}

(IRP) The standard temporal operators are implicit quantifiers over intervals which restrict the explicit individual quantifiers $(\forall, \exists)$ in their scope to things that are located within the relevant interval.

\footnotetext{
2 There are several other ways in which eternalists might try to block Deasy's argument. For example, they could argue against (SP) or against the applicability of (SP) to apparently tenseless statements such as (NIM). I will leave the discussion of these options for another occasion. See Deasy (2017b: 12-13) for a brief discussion of some options.
} 
Let us take an interval to be a set of temporally ordered instants, and let us assume that an interval can be instantaneous. ${ }^{3}$ Then (IRP) allows some cases in which temporal operators restrict the quantifiers to instants, just as (RP), but it also allows temporal operators to restrict quantifiers to non-instantaneous intervals. Which interval is in play depends (i) on the temporal operator and (ii) on the context of utterance. For example, the temporal operator 'now' will usually introduce a restriction to the instant of the utterance. ${ }^{4}$ So (IRP) delivers the same result as (RP) for (1), which on both principles comes out as (1.1):

(1) Right now, there exist dinosaurs.

(1.1) There exist dinosaurs, located at the present instant.

But (IRP) reflects that other temporal operators, including 'was' and 'will', are more likely to restrict the quantifiers to non-instantaneous intervals. Consider (4):

(4) There were several dinosaurs with beaks.

According to (RP), (4) has to be analysed as (4.1), where $t^{*}$ stands for a contextually determined instant prior to the instant of the utterance $t$.

(4.1) There exist several dinosaurs with beaks, located at instant $t^{*}$.

By contrast, the more flexible (IRP) can also deliver the following different analysis (4.2), in which $i$ stands for a contextually determined interval that is located before $t$.

(4.2) There exist several dinosaurs with beaks, located within interval $i$.

(4.1) and (4.2) have different truth-conditions: (4.1) requires there to be several contemporaneous dinosaurs with beaks located at an instant before $t$, while (4.2) is true even if no dinosaurs with beaks are contemporaneous, as long as there are several dinosaurs with beaks located within the relevant interval before $t$.

Below, I will argue that eternalists should favour (IRP) over (RP) and (Red). But how do eternalists in fact treat the matter? By briefly surveying what eternalists say about tense, I want to

\footnotetext{
${ }^{3}$ Nothing hangs on the terminological decision to admit instantaneous intervals. The principle could be amended to explicitly mention possible restrictions to instants or non-instantaneous intervals.

${ }^{4} \mathrm{It}$ is of course an idealisation that utterances are instantaneous. On a less idealised view of the duration utterances, the restriction will be to a non-instantaneous interval of (a part of) the utterance. I will ignore this complication here.
} 
bring out that there are few, if any, explicit eternalist endorsements of (RP). Some eternalists leave open whether tense and other temporal operators concern instants or intervals, others opt for approaches that conform with (IRP), and not with (RP).

To begin with, let us turn to Ted Sider's account of tense. As mentioned above, Deasy holds that Sider accepts (RP), and Sider does seem to lean towards (RP) in the following passage:

For the eternalist, past- and future-tensed claims are ultimately made true by claims that quantify over past and future times and entities. For instance, an assertion of $\ulcorner$ It was the case that $\phi\urcorner$ is true iff is true at some time located before that assertion. (2006: 77)

The fact that Sider talks about truth at a time suggests that he takes past-tensed sentences to concern instants located before the utterance. However, Sider then goes on to provide an analysis of a past-tensed statement that is compatible with both (RP) and (IRP):

Construing [5] [“Dinosaurs once existed.”] (somewhat artificially) as having this form, the eternalist thinks of [5] as amounting to:

[(5E)] There exist dinosaurs, located temporally before us.

$$
\exists x(\mathrm{D} x \& \mathrm{~B} x \mathrm{u})
$$

While this analysis states that (5) requires dinosaurs to be located temporally before the utterance, it leaves open whether the relevant temporal location is instantaneous or non-instantaneous. The view that Sider accepts (RP) is thus not unavoidable, and on a more charitable interpretation Sider can be seen as indecisive on this matter. ${ }^{5}$ The same holds for the eternalist analysis of tensed sentences provided by Quine (1960: 155); while Quine does not (to my knowledge) state that restrictions can be non-instantaneous, this is certainly compatible with what he says.

Other eternalists explicitly acknowledge that tensed sentences can concern intervals as well as instants. For example, Smart (2008: 228-229) states that eternalists can adopt Reichenbach's (1947) token reflexive account of tense, according to which (5) is analysed as (5T):

There exist dinosaurs earlier than this utterance.

On Reichenbach's account, tensed sentences are associated with reference times or reference events, and Smart makes clear that in analysing "imperfectives we need to refer to stretches of time" (2008:

\footnotetext{
${ }^{5}$ Elsewhere, Sider (2001: 26-27) discusses the question of whether presentists can treat certain operators as spanoperators, i.e. operators that concern some extended span (or interval) of time. He concludes that "the presentist must employ the slice tense operators" (2001: 27) and holds that presentists thus face a challenge in analysing "sentences that concern multiple times taken together" (ibid.). Although Sider does not in this context discuss eternalism, his line of argument seems to presuppose that eternalists can do better in analysing such sentences. (IRP) offers one way of providing such analysis, and thus fits well with what Sider says about span-operators. See Lewis (2004) and Brogaard (2007) on whether presentists can employs span-operators.
} 
229) (as reference times or reference events). Similarly, Ludlow (1999: Chapter 5) adopts Reichenbach's account of tense and highlights that reference times or reference events can be non-instantaneous. In particular, Ludlow notes that "temporal adverbs such as 'yesterday', 'today', and 'tomorrow' [...] can be construed as fixing the time of the reference event" (1999: 80), in which case the time of the reference event has to be non-instantaneous. And, finally, Mellor's (1998: Chapter 3) token-reflexive account of tense equally entails that sentences can concern non-instantaneous times.

A picture emerges on which those eternalists who pay attention to the question of whether tensed statements always concern instants or may also concern intervals vote in favour of accounts that fit with (IRP), and not with (RP). That is a problem for Deasy, as his reductio is based on the eternalist acceptance of (RP). ${ }^{6}$ With (IRP) in place rather than (RP), eternalists can avoid the aforementioned contradiction while having to give up neither (SP) nor (NIM). For (IRP), (SP) and (NIM) together merely imply the harmless and plausible (6):

(6) For some interval $i$, there is some $x$ and some $y$ located within $i$ such that there is no instant at which both $x$ and $y$ are located.

We thus have a first reason to be sceptical about Deasy's claim that eternalists must accept (Red).

A second reason to doubt Deasy's conclusion is given by the fact that (IRP) is independently plausible, as it is in line with the way contemporary semanticists treat tense in natural language which cannot be said of either (RP) or (Red). For example, (IRP) fits well with the following frequently-cited passage by Barbara Partee:

The deictic use of the Past tense morpheme appears in a sentence like [7]:

[7] I didn't turn off the stove.

When uttered, for instance, halfway down the turnpike, such a sentence clearly does not mean either that there exists some time in the past at which I did not turn off the stove or that there exists no time in the past at which I turned off the stove. The sentence clearly refers to a particular time - not a particular instant, most likely, but a definite interval whose identity is generally clear from the extra- linguistic context [...]. (1973: 602-603; italics mine)

Partee observes that uses of the past tense (a) depend on the context of utterance and (b) may concern intervals, not instants. The second of these points is nowadays widely shared by

\footnotetext{
${ }^{6}$ Deasy is not alone in holding that eternalists accept (RP). Marshall (2016), for example, claims that eternalists "typically endorse" (2016: 8) analyses of tensed statements that are in line with (RP). According to Marshall, this leads to a puzzle for eternalists; given that eternalists do not in fact analyse tensed statements in the way Marshall claims, the puzzle dissolves.
} 
semanticists, as is evident e.g. in von Stechow's (2009) review of contemporary theories of tense. Von Stechow sums up three of the main analyses of the past tense as follows:

(i) Past is an existential quantifier that instantiates the embedded VP to some time before the speech time; this view is attributed to tense logic, e.g. Prior (1967).

(ii) Past is a referring term denoting some contextually salient time before the speech time; this semantics is attributed to Partee (1973).

(iii) Past is a predicate that applies to a time $t$ and says that $t$ is before the speech time; this view originates perhaps with Dowty (1979). (2009: 129)

At first view, these approaches may seem to fall in line with (RP) because of the use of 'time' rather than 'interval'. But von Stechow makes clear that times are to be understood as "intervals composed of moments" (2009: 130). So, in fact, all three approaches fit with (IRP) (with respect to the question of whether tensed sentences may concern intervals), and not with (RP). And of course neither of the approaches entails that tense is redundant, so they clearly do not fit with (Red). ${ }^{7}$

At this point one might ask: Do theories of time have to conform with natural language semantics? That is a difficult question, but it certainly cannot do any harm for eternalists to adopt a principle that enjoys support from semantics. After all, the fact that a theory of time fits with how we talk is often brought forward as an argument in its favour. For example, it is frequently argued that one reason to accept presentism is its common-sense status (see e.g. Zimmerman 2008), and one way for a theory to fit with common sense is to fit with how we talk. A principle along the lines of (IRP) might help eternalists to counter this presentist appeal to common sense, while neither (RP) nor (Red) are promising in this respect.

Even if the conformity with natural language semantics is taken to be unimportant, there are good reasons for eternalists to accept (IRP) rather than (RP) or (Red), as Deasy's argument helpfully brings out. (RP) requires eternalists to give up the apparently plausible (SP) or (NIM). And (Red) turns a helpful definition of presentism into a claim that is trivial even from an eternalist perspective. We have seen that (IRP) does better in the first respect, and I will use the next section to show that it also does better in the second. I thus disagree with David Lewis, who remarks that eternalists can treat temporal operators in line with (IRP), but does not find restrictions to intervals of time "worth the bother" (2004: 13).

\footnotetext{
${ }^{7}$ Berit Brogaard (2007: 79) arrives at a very similar conclusion in her discussion of whether presentists can adopt span-operators (which concern intervals of time) or are confined to slice-operators (which concern instants of time), stating that "slice operators are often terrible candidates for the meaning of the English prefixes 'it has been that' and 'it will be that'".
} 


\section{Presentism, eternalism and where things are located}

Let us now return to the question of whether presentism can be adequately defined. Deasy's argument is meant to show that definition (P1) is trivial, even from an eternalist perspective:

(P1) The sentence 'Everything exists now' expresses a true proposition in every context of utterance.

With (IRP) in place, we can state the relevant reading of (P1) as follows:

$\left(\mathrm{P}_{\mathrm{LOC}}\right)$ The sentence 'Everything is located at the instant of this utterance' expresses a true proposition in every context of utterance.

The formulation of ( $\left.\mathrm{P}_{\mathrm{LOC}}\right)$ makes use of the flexibility of (IRP), which allows tensed statements to concern instants as well as intervals. (IRP) turns (P1) into ( $\left.\mathrm{P}_{\mathrm{LOC}}\right)$ due to the occurrence of 'now', which usually picks out the instant of the utterance (as mentioned above).

$\left(\mathrm{P}_{\mathrm{LOC}}\right)$ is not trivial from an eternalist perspective, for eternalists hold that some things are located before and some things after the instant of this utterance. Thus eternalists might define their view as follows:

(E $\left.E_{\mathrm{LOC}}\right)$ The sentence 'Some things are located before the instant of this utterance, some things are located at the instant of this utterance, and some things are located after the instant of this utterance' expresses a true proposition in every context of utterance.

And, indeed, similar definitions of presentism and eternalism have recently been proposed by Ross Cameron (2016: 127-128), though Cameron does not defend them against the argument I have been concerned with.

It thus becomes apparent that eternalists should rely on (IRP) rather than on (Red) in interpreting (P1). Furthermore, $\left(\mathrm{P}_{\mathrm{LOC}}\right)$ and $\left(\mathrm{E}_{\mathrm{LOC}}\right)$ show that there is another way to resist Deasy's argument against the presentism-eternalism debate: theorists can sidestep the question of whether eternalists should accept (RP), (IRP) or (Red) by making the intended interpretation explicit and providing definitions that are phrased in terms of where things are temporally located. Deasy does not consider such locational definitions, and they do not seem to inherit any of the problems of the other definitions he considers. 
But do these definitions adequately capture the disagreement between eternalists and presentists? Up to now, I have been concerned mainly with the eternalist perspective on the definitions. It seems clear that eternalists will accept $\left(\mathrm{E}_{\mathrm{LOC}}\right)$, and I have tried to show that they should not accept $\left(\mathrm{P}_{\mathrm{LOC}}\right.$ ), so from an eternalist perspective the dispute is clearly captured. How about the presentist perspective? Here, the answer is less obvious and depends on whether or not presentists accept the existence of instants of time. Let us focus on three presentist views on this matter: (i) a presentist view that reject the existence of instants of time altogether, (ii) a presentist view that accept the existence of the present time, while denying that non-present times exist or (iii) a presentist view that accepts the existence of both present and non-present times (while denying that non-present objects or events exist).

The first of these positions is adopted by Merricks (2007: Chapter 6):

In fact, I think presentists should deny that there is anything at all-much less some super-thin slice of being - that is the present time, just as they should deny that there are past times or future times. (2007: 124-125)

By the lights of this position, both $\left(\mathrm{E}_{\mathrm{LOC}}\right)$ and $\left(\mathrm{P}_{\mathrm{LOC}}\right)$ are clearly false. ${ }^{8}$ The sentences quoted in the definitions (e.g. 'Everything is located at the instant of this utterance' in $\left(\mathrm{P}_{\mathrm{LOC}}\right)$ ) contain the empty indexical 'this instant'. According to common ways of treating empty terms, this means that the sentences quoted are false or fail to express a complete proposition. As a result, the quoted sentences are clearly not true in every context of utterance, which means that $\left(\mathrm{E}_{\mathrm{LOC}}\right)$ and $\left(\mathrm{P}_{\mathrm{LOC}}\right)$ are clearly false. Given Merricks's outlook, the two definitions thus fail to do a good job at capturing the dispute between presentists and eternalists. But it seems that presentists should not follow Merricks in denying the existence of the present time, as I want to briefly argue.

Firstly, Merricks's argument for the view that presentists should deny that the present instant exists is not convincing. The argument is given in the following passage:

Now consider a view that starts with the eternalist's picture of time and existence at a time, and then 'shaves off the past and the future, leaving only a thin (instantaneous?) slice called 'the present'. This view agrees with eternalism that existing at a time - at any time, past, present, or future - is like being located at a place. But, unlike eternalism, this view says that while objects exist at the present time, they exist at no other times, since there are no other times at which to be located. Such a view implies that everything is instantaneous. [...] This view is not presentism. Presentists deny that everything is instantaneous; they think that many objects not only exist, but also have existed and will exist. (2007: 124)

It is questionable whether the view Merricks sketches indeed forces the presentist to hold that everything is instantaneous, as Cameron (2016: 135) has pointed out. Even if presentists accept that all there is is a thin slice of being, they can nonetheless hold that some things are such that

\footnotetext{
8 Thanks to an anonymous referee for highlighting this point. Tallant (2014) expresses sympathy for Merricks's view but does not explicitly rule out the existence of the present time.
} 
they have existed and will exist. So a view that accepts the existence of the present instant of time does not imply that everything is instantaneous, and, consequently, there is no reason for presentists to deny that the present instant of time exists.

Secondly, Merricks holds (rightly, it seems) that presentists should accept that "there are objects that exist at the present time" (2016: 125). But it is not clear whether presentists can accept this claim while denying that there is a present time. As far as I can see, the claim that there are objects that exist at the present time presupposes that there is a present time. It thus is doubtful, to say the least, that presentists should deny the existence of the present time, and, accordingly, doubtful that such a position presents a problem for the definitions I have proposed.

A more plausible presentist view on the matter denies only the existence of non-present times, while accepting that the present time exists; this is the second position mentioned above. Cameron (2016: 134-135) remarks that, from this point of view, ( $\mathrm{P}_{\mathrm{LOC}}$ ) will seem trivially true and $\left(\mathrm{E}_{\mathrm{LOC}}\right)$ trivially false. Given that only the present time exists, the sentence quoted in $\left(\mathrm{P}_{\mathrm{LOC}}\right)$ of course expresses a true proposition in every context of utterance. And if the sentence quoted in $\left(\mathrm{E}_{\mathrm{LOC}}\right)$ is read as stating that things are located at non-present times it again contains an empty term, making ( $\left.\mathrm{E}_{\mathrm{LOC}}\right)$ trivially false.

However, Cameron (2016: 136-138) not only highlights that presentists of the current ilk will take such a view on the definitions, but also convincingly argues that such a verdict is not a problem for the definitions: there can be a meaningful dispute between two theories even if, by the lights of one theory, the definition of the other is unintelligible or trivially false. What matters is that the definition of a theory is not seen as trivially true by the opposing theory, and that is not the case with $\left(\mathrm{P}_{\mathrm{LOC}}\right)$ and $\left(\mathrm{E}_{\mathrm{LOC}}\right)$ : presentists who accept only the existence of the present time do not take ( $\left.\mathrm{E}_{\mathrm{LOC}}\right)$ to be true, and eternalists do not agree with ( $\left.\mathrm{P}_{\mathrm{LOC}}\right)$, as I have argued above.

The third presentist view mentioned above accepts the existence of both present and nonpresent times (while denying that non-present objects or events exist). From this point of view, both $\left(\mathrm{P}_{\mathrm{LOC}}\right)$ and $\left(\mathrm{E}_{\mathrm{LOC}}\right)$ are intelligible, and none of indexicals involved are empty. Presentists of this kind will take $\left(\mathrm{P}_{\mathrm{LOC}}\right)$ to be true and $\left(\mathrm{E}_{\mathrm{LOC}}\right)$ to be false, so the view fits very well with the definitions proposed. But what reasons could presentists have to accept the existence of nonpresent times?

One motivation for this view is brought out by the prominent presentist Dean Zimmerman (2011: 197-203). Zimmerman argues that accepting non-present times allows presentists to respond to Sider's (2001: 25-35) objection that presentists do not have the resources to capture states of motion ascribed to objects by physics (without appealing to the now disregarded Newtonian view of absolute space). Presentists, the objection goes, can use tense operators to specify series of snapshots of the world, but they cannot "specify how the snapshots line up with 
other spatially, since such facts are not facts about what things are like at any one time" (2001: 32). According to Sider, this means that presentists cannot "capture certain facts about the states of motion of particles" (2001: 33).

However, Zimmerman shows that presentists can avoid this objection by accepting the existence of non-present times (while still denying the existence of non-present objects and events). These times could "preserve the distinctions between continuous and discontinuous, inertial and non-inertial paths taken by particles" (Zimmerman 2011: 199) and thus allow the presentist to capture the facts in question after all. In Zimmerman's view, adding such nonpresent times to the presentist ontology should not count as a significant cost:

Suppose I come to believe in a four-dimensional manifold with a specified structure because interactions among objects alone are not enough to explain why observable things behave as they do. Should this bother me, as a presentist? Not much, I think. [...] An A-theorist, like everyone else, should look to science for information about the structure of such things, including their metrical properties and the number of dimensions they have. My convictions about the unreality of past and future objects and events, on the other hand, are convictions about horses and wars and people: they have little to do with questions about what sorts of theoretical entities should be allowed to figure in scientific theories. (2011: 200)

There are thus good reasons for presentists to accept non-present times: on the one hand, it would be a significant cost to presentism if it were incompatible with contemporary physics; and on the other, the commitment to non-present times does not appear to go against the general spirit of presentism and its negative view of non-present objects and events.

Of course, some presentists may not find this approach attractive, and Zimmerman (2011: 202-203) himself argues that there are ways of answering Sider's objection that do not require the acceptance of non-present times. So not all presentists will accept non-present times. But even those who rule out such times should, as I have indicated, accept the existence of the present time and thus the second of the views discussed, which is compatible with the definitions proposed. Even from a presentist perspective, the proposed definitions thus seem to do well at capturing the dispute between presentists and eternalists.

\section{Conclusion}

I have argued that presentism and eternalism can be helpfully defined in terms of where things are located. If that is indeed the case, Deasy is too quick in calling the debate between presentists and eternalists unclear and in demanding that it should be abandoned in favour of the debate between transientists and permanentists. This suggests that theorists in temporal ontology should address both debates, which leads to interesting new questions about how positions in one 
debate can be plausibly combined with positions in the other. For example, do eternalists really have to be permanentists (and thus accept that always, everything exists forever), as Deasy (ms) argues? Is a version of permanentist presentism possible, according to which always, everything exists forever, but only things that are located at the instant of this utterance are concrete? In my view, it is worthwhile to look into these new questions rather than to dismiss the debate between presentists and eternalists as muddled.

\section{Acknowledgements}

For helpful discussion and comments, I would like to thank Alexander Dinges, Hugh Mellor, Julia Zakkou, several anonymous referees, as well as audiences at the workshop New Developments in the Philosophy of Time in Bonn and at the DGPhil conference in Berlin. Work on this paper was supported by a postdoc fellowship of the German Academic Exchange Service (DAAD).

\section{References}

Brogaard, B. 2007: Span operators. Analysis 67: 72-79.

Cameron, R. 2016: On characterizing the presentism/eternalism and actualism/possibilism debates. Analytic Pbilosophy 57: 110-140.

Deasy, D. 2017a: What is Presentism? Noûs 51: 378-397.

Deasy, D. 2017b: The Triviality Argument Against Presentism. Synthese: Online First.

Deasy, D. ms: Advanced Temporalising. Manuscript.

Dowty, D. 1979: Word Meaning and Montague Grammar: the semantics of verbs and times in generative semantics and in Montague's PTQ. Dordrecht: Reidel.

Lewis, D. 2004: Tensed quantifiers. Oxford Studies in Metaphysics 1: 1-14.

Ludlow, P. 1999: Semantics, Tense and Time. Cambridge, Mass.: MIT Press.

Marshall, D. 2016: A puzzle for modal realism. Philosophers' Imprint 16.19: 1-24.

Mellor, D. H. 1998: Real Time II. London: Routledge.

Merricks, T. 2007: Truth and ontology. Oxford: Oxford University Press.

Partee, B. H. 1973: Some structural analogies between tenses and pronouns in English. The Journal of Philosophy 70: 601-609.

Prior, A. 1967: Past, Present, and Future. Oxford: Oxford University Press.

Quine, W. V. O. 1960: Word and Object. Cambridge, Mass.: MIT Press.

Reichenbach, H. 1947: Elements of Symbolic Logic. New York: Macmillan. 
Sider, T. 2001: Four-dimensionalism: An Ontology of Persistence and Time. Oxford: Oxford University Press.

Sider, T. 2006: Quantifiers and temporal ontology. Mind 115: 75-97.

Smart, J. J. C. 2008: The tenseless theory of time. In: J. Hawthorne, T. Sider \& D. Zimmerman (eds): Contemporary Debates in Metaphysics. Malden, Mass.: Blackwell: 226-238.

von Stechow, A. 2009: Tenses in compositional semantics. In: W. Klein P. and Li (eds): The expression of time: Berlin: Mouton de Gruyter: 129-166.

Tallant, J. 2014: Defining existence presentism. Erkenntnis 79: 479-501.

Tallant, J. 2017: Presentism remains. Erkenntnis: Online First.

Williamson, T. 2013: Modal Logic as Metaphysics. Oxford: Oxford University Press.

Zimmerman, D. 2008: The Privileged Present: Defending an 'A-theory' of Time. In: J. Hawthorne, T. Sider \& D. Zimmerman (eds): Contemporary Debates in Metaphysics. Malden, Mass.: Blackwell: 211-225.

Zimmerman, D. 2011: Presentism and the Space-Time Manifold. In C. Callender (ed): The Oxford Handbook of Time. Oxford: Oxford University Press: 163-244. 